\title{
Stimulus conflict triggers behavioral avoidance
}

\author{
David Dignath $^{1} \cdot$ Andreas B. Eder $^{1}$
}

Published online: 1 May 2015

(C) Psychonomic Society, Inc. 2015

\begin{abstract}
According to a recent extension of the conflictmonitoring theory, conflict between two competing response tendencies is registered as an aversive event and triggers a motivation to avoid the source of conflict. In the present study, we tested this assumption. Over five experiments, we examined whether conflict is associated with an avoidance motivation and whether stimulus conflict or response conflict triggers an avoidance tendency. Participants first performed a color Stroop task. In a subsequent motivation test, participants responded to Stroop stimuli with approach- and avoidancerelated lever movements. These results showed that Stroopconflict stimuli increased the frequency of avoidance responses in a free-choice motivation test, and also increased the speed of avoidance relative to approach responses in a forced-choice test. High and low proportions of response conflict in the Stroop task had no effect on avoidance in the motivation test. Avoidance of conflict was, however, obtained even with new conflict stimuli that had not been presented before in a Stroop task, and when the Stroop task was replaced with an unrelated filler task. Taken together, these results suggest that stimulus conflict is sufficient to trigger avoidance.
\end{abstract}

Keywords Cognitive control · Approach-avoidance motivation · Stimulus conflict versus response conflict . Anterior cingulate cortex

A cognitive capacity that controls conflicts, failures, and losses is central to successful goal pursuit and well-being (Botvinick, Braver, Barch, Carter, \& Cohen, 2001; Ochsner \& Gross, 2008).

David Dignath

dignath.david@gmail.com

1 Department of Psychology, University of Würzburg, Röntgenring 10, 97070 Würzburg, Germany
For the scientific examination of cognitive control capacities, researchers have used "conflict tasks" in which the selection of a correct response to a target conflicts with an automatic and inappropriate response tendency instigated by an irrelevant task feature, such as the spatial position of a target (Simon task; Simon, 1969) or the perception of distracting stimuli (flanker task; Eriksen \& Eriksen, 1974). In the classic Stroop task (Stroop, 1935; for a review, see MacLeod, 1991), for instance, participants must classify the ink color of a written word (the relevant feature) while ignoring the meaning of the word (the irrelevant feature). Responses are typically faster and less errorprone in congruent trials, in which the irrelevant feature affords the same response as the target feature (e.g., the word RED printed in red), than in incongruent trials, in which the relevant and irrelevant features afford different responses (e.g., the word RED printed in green).

Researchers examining neural activity during the performance of a Stroop task have observed that activity in the anterior cingulate cortex (ACC) is increased during performance in incongruent relative to congruent trials (Carter et al., 1998). This neural activity has been interpreted as evidence for a conflict detection function of the ACC (Botvinick et al., 2001; Botvinick, Cohen, \& Carter, 2004; Botvinick, Nystrom, Fissell, Carter, \& Cohen, 1999). The conflict signal is then transmitted from the ACC to an executive unit- the dorsolateral prefrontal cortex (DLPF) - that amplifies the task-relevant dimensions (Egner \& Hirsch, 2005) and inhibits responses instigated by task-irrelevant dimensions (Stürmer, Leuthold, Soetens, Schröter, \& Sommer, 2002). Research has also shown that the ACC is involved in affective and motivational processes during decision making (Carter, Botvinick, \& Cohen, 1999; Holroyd \& Coles, 2002; Holroyd \& Yeung, 2012; Shackman et al., 2011). For instance, lesions of the ACC have been shown to cause akinetic mutism - a neurological disorder that is characterized by a strong reduction of motivated action, despite intact motoric abilities (Németh, Hegedüs, \& Molnâr, 1988). 


\section{Conflict is registered as an aversive signal}

Botvinick (2007; see also Shenhav, Botvinick, \& Cohen, 2013) has integrated the two functions in a single model by proposing that conflict detected by the ACC creates an aversive signal and that this signal guides adjustments to conflict and motivates avoidance learning. The hypothesis that the ACC monitors aversive signals has been supported by neuroimaging (Eisenberger, Lieberman, \& Williams, 2003; Rainville, 2002; Singer et al., 2004) and behavioral (Dreisbach \& Fischer, 2012; Fritz \& Dreisbach, 2013; Schouppe, De Houwer, Ridderinkhof, \& Notebaert, 2012) studies.

Supportive evidence for a negative evaluation of conflictinducing stimuli has come from a study by Dreisbach and Fischer (2012). They presented congruent and incongruent Stroop displays as primes shortly before a target word with a clear positive or negative meaning. Participants' task was to classify the valence of the target as quickly and accurately as possible (affective priming task, Fazio, Sanbonmatsu, Powell, \& Kardes, 1986). Their results showed that the congruency level of the Stroop primes affected performance in the evaluative categorization task: Reactions times (RTs) for negative targets were shorter with incongruent Stroop primes than with congruent Stroop primes, and vice versa for positive targets. Evidence suggesting that conflict motivates avoidance has come from a recent study by Schouppe and colleagues (2012). Their participants responded to the color of a Stroop stimulus by moving a virtual manikin on the computer screen toward the stimulus (approach) or away from it (avoidance). The results showed that a Stroop effect was eliminated with avoidance movements, suggesting that conflict promotes avoidance. Interpretation of these findings is, however, compromised by the unbalanced exposures to congruent and incongruent Stroop items in these studies. Specifically, congruent items were presented three times more frequently than incongruent items. This difference is problematic, because stimulus repetitions are known to affect evaluative judgments (the so-called mere-exposure effect; Bornstein, 1989). Thus, differences in affective evaluations (Dreisbach \& Fischer, 2012) or in the size of the Stroop effects for approach/ avoidance actions (Schouppe et al., 2012) could be alternatively explained by a positive valence of the congruent Stroop items, obtained through their more frequent exposures.

\section{Stimulus conflict and response conflict in Stroop tasks}

Another important aspect of the conflict monitoring theory and its recent extension pertains to the question how conflict is measured. Originally, conflict is conceptualized as the degree to which incompatible response units are simultaneously activated (Botvinick et al., 2001) - that is, a conflict between stimuli and responses (response conflict; cf. Kornblum, Hasbroucq, \& Osman, 1990). However, conflict can also arise between different between features of stimuli (stimulus conflict). In the conflict-monitoring theory, response conflict and not stimulus conflict is modeled to generate the (aversive) conflict signal registered by the ACC (Botvinick et al., 2001; see also Cohen, Dunbar, \& McClelland, 1990). It is unclear whether the notion of a negative conflict that serves as a signal for avoidance can be extended to stimulus conflict, as well.

With respect to affective stimulus evaluations, Fritz and Dreisbach (2013, Exp. 1b) showed that stimulus conflict is sufficient to trigger a negative evaluation. Incongruent Stroop items were evaluated in this study more negatively without prior training in a Stroop task, ruling out response conflict as a trigger of the negative evaluation. Schouppe and colleagues (2012), on the other hand, disentangled stimulus and response conflict as sources of an avoidance tendency by mapping two (of four) colors to either the same response or different responses. With a mapping to identical responses, incongruent Stroop displays would elicit only stimulus, but not response, conflict (stimulus-incongruent trials), whereas they would induce both types of conflict when the colors were mapped onto different responses (response-incongruent trials). Thus, subtracting incongruent stimulus trials from incongruent response trials could be used as a proxy of stimulus conflict processing. RTs for approach movements increased linearly, from congruent to stimulus-incongruent to response-incongruent trials. For avoidance responses, however, a congruency effect emerged only in congruent versus response-incongruent trials, but not in congruent versus stimulus-incongruent trials. The authors suggested on the basis of this result that stimulus conflict, and not response conflict, triggers avoidance. Indeed, a facilitation of avoidance movements could explain the reduced congruency effect in stimulus-incongruent trials, in comparison with responseincongruent trials.

However, an alternative interpretation is possible as well. Consider the proportions of congruent and incongruent trials in this task: Whereas congruent trials comprised $50 \%$ of the trials, stimulus-incongruent trials (i.e., incongruent stimuli that afforded the same response) and response-incongruent trials (i.e., incongruent stimuli that afforded different responses) comprised only $25 \%$ of the trials each. Given these proportions, the irrelevant dimension was predictive of the correct response on $75 \%$ of the trials, and attention was directed toward the irrelevant dimension (Logan \& Zbrodoff, 1979). As a consequence, response selection benefited from a predictive relationship with the irrelevant stimulus dimension in the stimulus-incongruent trials, but not in the responseincongruent trials, explaining the difference between the two conditions with a difference in consistency proportions. Thus, 
it cannot be firmly concluded from this study that stimulus conflict was the primary source of conflict avoidance.

\section{Outline of the present research}

The aim of the present study was to provide a more conclusive test of the relationship between conflict experiences in Stroop tasks and avoidance motivation. Animal and human research has pointed out that one must be cautious in inferring motivational urges from measurements of affective experiences, because (i)negative stimuli can also evoke a motivational urge to approach (Berkowitz \& Harmon-Jones, 2004; Carver \& Harmon-Jones, 2009; Scholer \& Higgins, 2008) and (ii) approach motivation is occasionally experienced as a negative affective state (Berridge, Robinson, \& Aldridge, 2009; Carver, 2004; Harmon-Jones, Harmon-Jones, \& Price, 2013). In short, approach and avoidance motivations are dissociable from positive and negative affective states; consequently, more direct evidence is needed to evaluate the theoretical claim of a motivational avoidance of conflict-inducing stimuli.

One research goal was to rule out mere exposure as an alternative explanation for this relationship. A second goal was to clarify whether stimulus or response conflict triggers an avoidance tendency. To address these questions, each experiment consisted of two phases: First, participants performed a manual version of the color Stroop task with congruent and incongruent color words. Following the procedure of Dreisbach and Fischer (2012), these Stroop trials served to activate experiences of conflict during the processing of color words. In a subsequent motivation approach-avoidance test (AAT), participants responded to the Stroop stimuli by means of pulling and pushing lever movements, which were associated with approach and avoidance, respectively (M. Chen \& Bargh, 1997; Eder \& Rothermund, 2008). Participants were to respond in this task to both dimensions of the Stroop stimulithe ink color and the meaning of the word - by sorting these stimuli into one-color words (congruent items) and two-color words (incongruent items). In contrast to the classic Stroop task, in which both dimensions of a Stroop stimulus instigate different responses and cause response conflict, responding to both dimensions simultaneously should only cause stimulus conflict. This AAT probed for motivational action tendencies in the absence of response conflict.

In line with the first research goal, in Experiments 1a and $1 \mathrm{~b}$ we aimed to validate the conclusions of earlier research using an improved task procedure. In line with the research of Schouppe et al. (2012), it was hypothesized that the congruency level of the Stroop items affects the selection of approach- and avoidance-related lever movements in the AAT: Incongruent color words should facilitate avoidance relative to approach, whereas congruent color words should promote approach relative to avoidance. Such a conflict- avoidance bias would confirm that conflict stimuli trigger an avoidance tendency. Importantly, individual Stroop items were presented with the same frequencies throughout the experiment, to exclude differences in "mere exposure" as an alternative explanation of motivational action tendencies.

Regarding the second research goal - to specify the level of conflict that causes a conflict-avoidance bias - two, alternative accounts appear tenable: First, it is possible that the prior Stroop-conflict experience had no influence on the performance in the AAT. According to this account, the motivational response measured in the AAT was caused by the conflicting stimulus features that are inherent to Stroop stimuli. We term this the stimulus-conflict account. Alternatively, it is possible that participants learned in the Stroop task to associate specific Stroop items (or a category of items) with experiences of conflict. In the subsequent AAT, presentations of incongruent color words then triggered automatic retrieval of the previous conflict experience. We term this the conflict-learning account. It should be noted that the learning account does not differentiate between memories of stimulus and response conflicts. In Experiments 1a and 1b, we addressed this issue with correlation analyses. In particular, we were interested in whether participants who experienced enhanced conflict in the first phase (as indexed by an enhanced Stroop congruency effect in the first phase) would show increased conflictavoidance biases in the second phase (AAT). Experiments $2 \mathrm{a}$ and $2 \mathrm{~b}$ tested a conflict-learning account of conflict avoidance. We manipulated the strength of item-conflict associations directly by administering different proportions of incongruent trials. In line with previous research on consistency proportion effects in Stroop tasks (e.g., Logan \& Zbrodoff, 1979), we expected that a high proportion of incongruent trials would produce less conflict than a low proportion of incongruent trials. If associations with conflict experience are established in the Stroop task and automatically retrieved during the processing of Stroop items in the subsequent AAT, then the conflict-avoidance bias should be a function of conflict strength. Finally, in Experiment 3 we tested a stimulusconflict account of conflict avoidance. In one group, the color Stroop task was replaced by an unrelated filler task, whereas another group performed the color Stroop task before the motivational test (AAT); by means of this procedure, we could examine whether learning of stimulus-conflict associations is causal to a conflict-avoidance bias in the AAT (conflict-learning account), or whether conflicting stimulus features, in the absence of response conflict, are sufficient to induce a conflict-avoidance bias in the AAT without prior learning (stimulus-conflict account).

\section{Experiments 1a and 1b}

Both experiments followed the general procedure outlined above and differed only in the setup of the motivation test. 
In Experiment 1a, the AAT was a free-choice test. Upon the presentation of a color word, participants could freely decide whether they wanted to carry out an approach- or avoidancerelated movement. Participants reacted to the appearance of a color word, without an explicit request for a categorization. Thus, no stimulus labels were needed for this version of the AAT, ruling out a possible confound with affective stimulus labels (Eder \& Rothermund, 2008). In Experiment 1b, the AAT was a forced-choice test. Participants categorized color words as quickly and accurately as possible according to predefined stimulus-response instructions that mapped (congruent) one-color words and (incongruent) two-color words onto either approach or avoidance movements. In line with previous work (Dreisbach \& Fischer, 2012; Schouppe et al., 2012), we expected that the congruency level of the color word would bias the selection of avoidance and approach responses in the AAT. Avoidance responses should be more frequent (Exp. 1a) and be selected faster (Exp. 1b) in response to incongruent color words (relative to congruent color words), whereas approach responses should be selected more frequently (Exp. 1a) and faster (Exp. 1b) in response to congruent color words (relative to incongruent color words). Correlation analyses additionally examined whether the magnitude of the congruency effect in the Stroop task was related to a conflict-avoidance bias in the subsequent AAT.

\section{Method}

\section{Participants}

Fifty-two students at the University of Würzburg were paid for participation in Experiment 1a (four left-handed; 39 women, 13 men; mean age $=24.6$ years, range: $18-54$ years). The data of one participant were removed due to an unusually high error rate in the AAT $(M=20 \%$; $>3 S D$ s beyond the group mean of $1.3 \%$ ). Forty-four students participated in Experiment 1b (five left-handed; 42 women, two men; mean age $=23.2$ years, range: $18-38$ years $)$. The data of two participants were removed from the analyses due to unusual high error rates in the AAT $(M \geq 41 \%$; $>3 S D$ s beyond the group mean of $10.4 \%$ ).

\section{Stimuli}

The color words were the German words for BLUE, GREEN, YELLOW, and RED printed in blue, green, yellow, or red. For one-color words, the print color of the word matched the meaning of the word, whereas for two-color words, the colors mismatched. Only four combinations of two-color words were presented to a specific participant, to ensure the presentation of individual congruent and incongruent Stroop items in equal frequencies. For this subset of incongruent color words, the assignment of the ink color to the meaning of the color word was counterbalanced across participants. All stimuli were written in Calibri and subtended $21.36^{\circ}$ (width) $\times 5.87^{\circ}$ (height) of visual angle, measured from a viewing distance of $50 \mathrm{~cm}$. A white "+" was used as a fixation cross and subtended $1.15^{\circ}$ of visual angle in width and height.

\section{Procedure}

Stroop task This task was introduced to the participants as a "color sorting task." They were instructed to respond to the ink color of a word by pressing the "a," "f," "l," or "\#” key using the index and middle fingers of their left and right hands. The assignment of the response buttons to the ink colors was counterbalanced across participants. At the start of a trial, a fixation cross was presented for $300 \mathrm{~ms}$, followed by a colored word that prompted the participant to respond as quickly as possible. After 1,000 ms, a blank screen was presented until the registration of a keypress. In the case of an incorrect or late response (RT $>1,000 \mathrm{~ms}$ ), an error message appeared for 1, $000 \mathrm{~ms}$. The next trial started after an intertrial interval (ITI) of 1,000 ms. The Stroop task consisted of three blocks with eight congruent and eight incongruent trials each (cf. Dreisbach \& Fischer, 2012).

AAT (motivation test) This task was described to the participants as the "word sorting task." Participants responded to the onset of a color word by pulling a joystick lever to the body (approach) and by pushing the lever away from the body (avoidance). For additional references to approach and avoidance, the lever movements were linked to visual illusions of word movements toward and away from the participant ("zoom effect"; see Rinck \& Becker, 2007). The size of the word increased (by a factor of 3.5) after the registration of a lever pull, and decreased (by a factor of 0.1 ) after the registration of a lever push, for a duration of $300 \mathrm{~ms}$ (with a rate of 33 pictures/s). One-color (congruent) and two-color (incongruent) words were presented in a random order. A white fixation cross was presented for $300 \mathrm{~ms}$ at the start of a trial, followed by a color word that prompted the participant to respond with a lever movement. After 1,000 ms, a blank screen was presented until the registration of a lever movement. In the cases of wrong or late responses (RTs $>2$, $000 \mathrm{~ms}$ ), an error message appeared for 1,000 ms (instead of the zoom effect). The next trial started after an ITI of 1 , $000 \mathrm{~ms}$. No practice trials were administered, in order to facilitate a learning transfer to the motivational test.

In Experiment 1a, the instructions stated that participants should freely select whether to pull a color word toward their body or push it away from their body. The instructions also stated that both movement types should be performed about equally often in a block, and that response strategies like single or alternating responses in a fixed sequence were not 
permitted. To minimize the preparation of response strategies prior to stimulus presentation, half of the trials were no-go trials, which were indicated by the letters "XXXX" printed in gray color. Here, participants were to refrain from a response (for a similar procedure, see Elsner \& Hommel, 2001). An error message appeared for $1,000 \mathrm{~ms}$ in the cases of responses in no-go trials or late responses in go trials (RT > $2,000 \mathrm{~ms}$ ). The free-choice AAT consisted of 20 blocks with eight go trials (four congruent and four incongruent color words) and eight no-go trials each. After each block, participants received feedback about their errors and response choices.

In Experiment $1 \mathrm{~b}$, the instructions stated that two types of color words would be shown during the AAT: one-color words that referred to only one color, and two-color words that referred to two different colors. The stimulus-response instructions specified whether participants should respond to one-color words with an approach-related lever movement and to two-color words with an avoidance-related lever movement, or vice versa. There were 24 blocks with 16 trials each (eight one-color, eight two-color words). The assignment of lever responses to the color words (one-color vs. two-color) changed after 12 blocks (the order of the instructions was counterbalanced across participants). ${ }^{1}$ After each block, participants received feedback about their mean $\mathrm{RT}$ and error rate.

\section{Results}

\section{Stroop task}

\section{Experiment 1 a}

Reaction times Anticipations (6.4\%), omissions (10.6\%), wrong responses $(10.4 \%)$, and RTs that deviated more than three $S D$ s from the corresponding cell mean $(0.2 \%)$ were removed from the RT analyses, resulting in empty cells $(N<$ $10)$ for five participants, who were removed from the analyses. As expected, responses to incongruent color words were slower $(M=671 \mathrm{~ms}, S D=88 \mathrm{~ms})$ than responses to congruent stimuli $(M=610 \mathrm{~ms}, S D=88 \mathrm{~ms}), t(45)=7.67, p<.001, d=$ 1.05 .

Error rates Errors were more frequent in incongruent trials $(M=34.6 \%, S D=20.7 \%)$ than in congruent trials $(M=$ $21.1 \%, S D=15.8 \%), t(50)=6.64 p<.001, d=0.93$, corroborating the results of the RT analysis.

\footnotetext{
${ }^{1}$ Surprisingly, the mapping order affected the conflict-avoidance bias in the AAT, in that participants who began to categorize incongruent (vs. those beginning on congruent) color words with avoidance (vs. approach) responses showed no conflict-avoidance bias. However, Experiment $2 \mathrm{~b}$ did not replicate this finding (no interaction with other factors).
}

\section{Experiment $1 b$}

Reaction times Trials with RTs faster than 100 ms were considered anticipations (6.8 \%), and trials slower as $1,000 \mathrm{~ms}$ as omissions (11.4\%). Trials with wrong responses (11.1\%) and RTs that deviated more than three $S D$ s from the corresponding cell mean $(0.1 \%)$ were considered outliers. These trials were excluded from the RT analyses, resulting in empty cells $(N<$ 10) for six participants. The data of these participants were not analyzed further. Responses to incongruent stimuli took significantly longer $(M=670 \mathrm{~ms}, S D=74 \mathrm{~ms})$ than responses to congruent stimuli $(M=609 \mathrm{~ms}, S D=67 \mathrm{~ms}), t(35)=6.35, p<$ $.001, d=1.05$.

Error rates As in Experiment 1a, responses to incongruent color words were more error-prone $(M=37.3 \%, S D=$ $20.5 \%)$ than responses to congruent color words $(M=$ $21.3 \%, S D=19.6 \%), t(41)=7.25, p<.001, d=1.12$.

\section{AAT}

\section{Experiment 1a}

Trials with response anticipations $(0.1 \%)$ or response omissions $(0.4 \%)$ and trials with incorrect movements to the left or right $(2.3 \%)$ were removed from the analyses. To control for the aftereffects of response inhibition, we also computed all analyses for free-choice AATs after the removal of post-no-go trials. These analyses (not reported) yielded identical results. Error responses in the no-go trials were rare $(M=1.4 \%, S D=$ $1.5 \%$ ). Exploratory analyses of the RTs revealed only main effects and no interactions in all free-choice AAT experiments, and are not reported further.

Response choice As is shown in Fig. 1 (left panel), participants selected approach more often than avoidance as a response to congruent color words ( $M=53.9 \%, S D=13.9 \%$ ), $t(50)=2.04, p=.046, d=0.28$. In response to incongruent color words, avoidance was preferred $(M=55.0 \%, S D=$ $11.4 \%), t(50)=3.12, p=.003, d=0.44$.

\section{Experiment $1 b$}

Reaction times Trials with response anticipations (RTs < $100 \mathrm{~ms} ; 2.9 \%$ ) or response omissions (RTs $>2,000 \mathrm{~ms}$; $0.2 \%$ ), trials with joystick movements in the left and right directions (3.3\%), and trials with incorrect responses (5.9\%) and with RTs that deviated more than three $S D$ s from the corresponding cell mean $(1.2 \%)$ were excluded from the RT analyses. To control for the aftereffects of errors, we also computed all analyses for forced-choice AATs after the removal of posterror trials. These analyses (not reported) yielded identical results. 


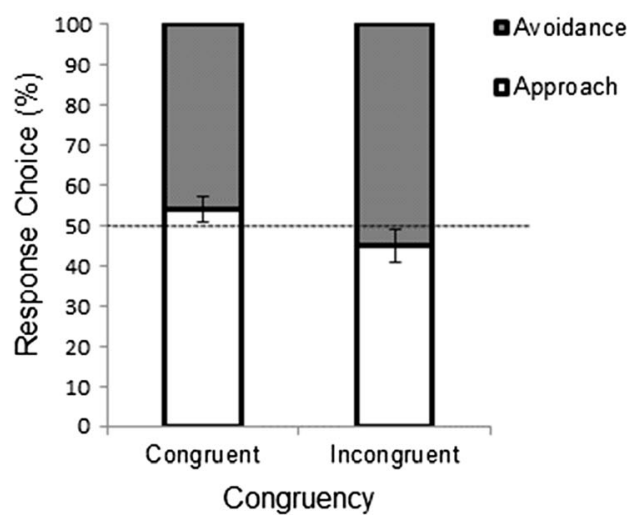

Fig. 1 (Left)Mean response choices for congruent and incongruent stimuli in the free-choice approach-avoidance test (AAT) of Experiment 1a. (Right)Mean reaction time (RT) as a function of stimulus congruency

A repeated measures analysis of variance (ANOVA) with the factors Congruency (congruent vs. incongruent color words) and Response Type (approach vs. avoidance movements) yielded a main effect of congruency, $F(1,41)=38.93$, $p<.001, \eta_{\mathrm{p}}{ }^{2}=.487$, with faster reactions to congruent color words $(M=679 \mathrm{~ms})$ than to incongruent color words $(M=$ $709 \mathrm{~ms})$. The main effect of response type was also significant, $F(1,41)=8.81, p=.005, \eta_{\mathrm{p}}{ }^{2}=.177$. Approach responses were generally executed faster than avoidance movements $(M \mathrm{~s}=687$ vs. $702 \mathrm{~ms})$. Most importantly, the interaction between congruency and response type was significant, $F(1,41)=13.26$, $p<.001, \eta_{\mathrm{p}}{ }^{2}=.244$. As is shown in Fig. 1 (right panel), participants were faster to approach congruent color words ( $M=643 \mathrm{~ms}, S D=121 \mathrm{~ms}$ ) than to approach incongruent color words $(M=730 \mathrm{~ms}, S D=129 \mathrm{~ms}), t(41)=5.47, p<.001$, $d=0.84$. The latencies of avoidance responses did not differ significantly, $t(41)=1.58, p>.05$.

Error rates An analogous repeated measures ANOVA with the factors Congruency (congruent, incongruent) and Response Type (approach, avoidance) showed a significant interaction between congruency and response type, $F(1,41)$ $=32.07, p<.001, \eta_{\mathrm{p}}{ }^{2}=.439$. Follow-up $t$ tests revealed that avoidance responses to incongruent color words $(M=4.4 \%$, $S D=3.9 \%$ ) were less error-prone than avoidance responses to congruent color words $(M=8.1 \%, S D=5.6 \%), t(41)=5.05$, $p<.001, d=0.79$. In contrast, errors were more frequent when executing an approach response to incongruent words $(M=8.3 \%, S D=5.3 \%)$ than for approach responses to congruent words $(M=4.6 \%, S D=4.2 \%), t(41)=5.49, p<.001$, $d=0.84$. All other effects were not significant (with $p s>.700$ ).

\section{Correlation analyses: Experiments $1 a$ and $1 b$}

A Stroop interference effect was calculated for each participant. Because high error rates in the Stroop task produced

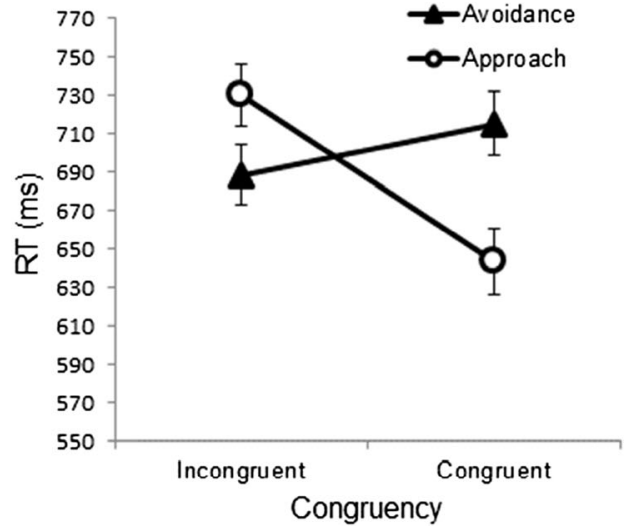

and response type for the forced-choice AAT of Experiment 1b. Error bars show standard errors of the paired differences (Pfister \& Janczyk, 2013)

missing RT data for some participants (see above), we computed Stroop interference effects on the basis of the error rates (i.e., Stroop interference $=$ Errors in incongruent Stroop trials Errors in congruent Stroop trials). An index for conflictavoidance bias was computed separately for response choices [Exp. 1a: (Avoidance response for incongruent- Approach response for incongruent) + (Approach response for congruent- Avoidance responses for congruent)/2] and for RTs and error rates [Exp. 1b: (Avoidance response for congruentAvoidance response for incongruent) + (Approach response for incongruent- Approach responses for congruent)/2]. The results showed that participants who displayed a stronger congruency effect in the Stroop training exhibited a stronger conflict-avoidance bias in the AAT (Exp. 1a: response choices, $r=.320, p=.011$, one-sided; Exp. 1b: RTs, $r=.296, p=.029$, one-sided; error rates, $r=.291, p=.031$, one-sided).

\section{Discussion}

Experiments $1 \mathrm{a}$ and $1 \mathrm{~b}$ investigated whether incongruent Stroop color words facilitate avoidance, whereas congruent Stroop color words facilitate approach. The results supported this prediction. In Experiment 1a (free-choice AAT), participants preferred avoidance as a response to incongruent items and approach as a response to congruent color words. An analogous pattern was observed with a forced-choice AAT (Exp. 1b). Here, an avoidance response was executed faster and with fewer errors in response to incongruent color words than to congruent color words. This finding of a conflictavoidance bias is line with previous studies on the affective evaluation of conflict (Dreisbach \& Fischer, 2012) and replicates the study by Schouppe and colleagues (Schouppe et al., 2012), yet without confounding the level of congruency with the frequency of stimulus presentation. This is particular 
important, because it rules out an alternative explanation of the conflict-affect link in terms of liking differences related to mere exposure. Furthermore, the go/no-go task structure in Experiment 1a ruled out a correspondence between explicitly instructed stimulus labels and approach-avoidance response as an alternative explanation of the effect (Eder \& Rothermund, 2008).

However, the results are only suggestive regarding the level of processing that caused the conflict. According to the conflict-learning account, participants learned in the Stroop task to associate specific stimuli with conflict; these conflict experiences were then automatically retrieved in the subsequent motivation test (AAT). The stimulus-conflict account, on the other hand, expects no transfer from the Stroop task to the AAT. The observed correlation between the Stroop effect and the conflict-avoidance bias is more in line with the former assumptions: Participants who had more difficulties responding to incongruent color words in the Stroop task also exhibited more avoidance of these items in the subsequent motivational test. This relationship fits with the idea that conflict memories were retrieved during the AAT, but caution is warranted with this interpretation of correlative evidence. On the one hand, error rates in the Stroop task were unusually high. Possibly, memorizing a complex mapping between four colors and keys without practice and with only a few trials to perform the task (following task procedures used by Dreisbach \& Fischer, 2012) could have obscured the assessment of conflict effects. On the other hand, it is possible that the correlation indexed interindividual differences in sensitivity to conflict information and not differences in memories of conflict. Therefore, experimental work was still needed to examine any causal role of conflict experiences for the conflict bias more rigorously.

\section{Experiments 2a and 2b}

In Experiments $2 a$ and $2 b$, we systematically manipulated the magnitude of conflict induced by congruent and incongruent Stroop items. One way to do so is to change the proportions of congruent to incongruent stimuli. Stroop interference effects (i.e., faster responses to congruent than to incongruent color words) are typically larger with a low proportion of incompatible trials, but decreased (or even reversed in direction) with a high proportion of incompatible trials (see, e.g., Lindsay \& Jacoby, 1994; Logan \& Zbrodoff, 1979; Tzelgov, Henik, \& Berger, 1992). One explanation of a list-wide proportion congruency effect (PC) is a sustained shift in the attention paid to the task-relevant and task-irrelevant dimensions (Abrahamse, Duthoo, Notebaert, \& Risko, 2013). With different proportions of congruent and incongruent color words, attention to the relevant print color is relaxed, such that the influence of the irrelevant meaning of the word increases. As a consequence, incongruent color words produce less interference when the proportion of incongruent trials is high, whereas they produce more interference when the proportion is low. Conflictmonitoring theory accounts for PC effects by assuming that the conflict signal is cumulatively computed at the response level over a series of trials and used to strengthen or weaken, respectively, the relevant or irrelevant dimension (Botvinick et al., 2001). Attentional modulations induced by PC also transfer to new situations with equally balanced proportions (Torres-Quesada, Funes, \& Lupiáñez, 2013), and PC effects have been shown to generalize to other conflict tasks (TorresQuesada, Lupiáñez, Milliken, \& Funes, 2014).

For Experiment 2a we used a free-choice AAT, and for Experiment $2 \mathrm{~b}$ a forced-choice AAT. Critically, in both experiments the strength of conflict in the Stroop task was manipulated by administering different proportions of incongruent trials in a block. In line with previous research on list-wide PC effects, incongruent Stroop items should produce less response conflict when they are embedded in a block trial list with a high proportion of incongruent trials than in a block list with a low proportion of incongruent Stroop items. If different levels of conflict indeed become associated with the eliciting situations, as the conflict-learning account suggests, then the avoidance of incongruent color words in the AAT should be reduced (vs. increased) following a PC condition with a high (vs. a low) proportion of incongruent trials, relative to a baseline condition with equal proportions of incongruent and congruent trials.

In addition, in Experiment $2 \mathrm{~b}$ we introduced new, untrained color words during the AAT, together with the trained color words that had been used in the Stroop task. The conflict-learning account would assume transfer from the Stroop task to the AAT for trained but not for untrained color words. In contrast, the stimulusconflict account would expect a conflict-avoidance bias for both trained and new color words.

\section{Method}

\section{Participants}

Ninety-seven students were paid for their participation in Experiment 2a (eight left-handed; 75 women, 22 men; mean age $=24.5$ years, range: $18-56$ years), and 68 students took part in Experiment 2b (three left-handed; 49 women, 19 men; mean age $=27.5$ years, range: $18-62$ years). For each experiment, participants were randomly assigned to one of three PC conditions. The data of three participants in Experiment 2a and one participant in Experiment $2 \mathrm{~b}$ were removed due to unusually high error rates in the AAT $(M \mathrm{~s} \geq 46 \% ;>3 S D \mathrm{~s}$ beyond the respective group mean of $7.7 \%$ ). 


\section{Stimuli and procedure}

The stimuli were the same as in the previous experiments. In the Stroop task, participants classified two different ink colors with presses of the keys " $d$ " or " 1 ," using the index finger of the left or the right hand. Each participant responded to only two of the four possible colors, resulting in two congruent and two incongruent color words. The assignments of the colors to the response keys were counterbalanced across participants. ${ }^{2}$ Depending on the PC condition, incongruent color words appeared in $20 \%$ (high conflict), $50 \%$ (baseline), or $80 \%$ (low conflict) of a block's trials. The same color words that were presented during the Stroop task were also presented during the AAT. In Experiment 2a, the AAT was a free-choice task, identical to that in Experiment 1a. The experiment started with a block of 96 Stroop trials, followed by a block of 48 AAT trials. Half of the trials in the AAT block were no-go trials, whereas the other half comprised trials with color words (50\% congruent and incongruent color words). This sequence was repeated three times. Experiment 2b (forced-choice AAT; see Exp. 1b) started with a block of 180 Stroop trials (50\% incongruent color words), followed by a block of 192 AAT trials. This sequence was repeated once. The stimulus-response mapping was reversed after the first AAT block. The order of the mappings was counterbalanced across participants.

Critically, research has shown that the colors red and green can have affective connotations (e.g., Elliot \& Maier, 2007). To control for this potential confound, we computed for the $20 \%$ and $80 \%$ groups the factor Affect Color (green vs. nogreen). This factor did not interact with the conflict bias, $F<1$. Furthermore, we ran the same analysis for the $50 \%$ group. Here, one of the two colors was always red. Thus, we contrasted red and neutral color combinations with red and green color combinations. Again, this factor did not interact with the conflict bias, $F<1$.

\section{Results}

\section{Stroop task}

\section{Experiment $2 a$}

Reaction times Anticipations (0.9\%), omissions (0.8\%), wrong responses $(2.6 \%)$, and RTs that deviated more than three $S D$ s from the corresponding cell mean $(0.2 \%)$ were

\footnotetext{
${ }^{2}$ Due to a programming error, the counterbalance algorithm malfunctioned. More precisely, the color words for the $20 \%$ - and $80 \%$-incongruent groups always comprised combinations of yellow/ blue, yellow/green, or green/blue within a Stroop stimulus, but never included red. In contrast, for the $50 \%$-incongruent group, the Stroop stimuli always included red at one level, in combination with one of the colors yellow, green, or blue.
}

removed from the RT analyses. A repeated measures ANOVA with the factors Congruency (congruent, incongruent) and PC (20\% incongruent, $50 \%$ incongruent, $80 \%$ incongruent) yielded a main effect of congruency, $F(1,91)=$ $15.81, p<.001, \eta_{\mathrm{p}}{ }^{2}=.148$, and an interaction effect, $F(2,91)$ $=8.38, p<.001, \eta_{\mathrm{p}}{ }^{2}=.156$. Post-hoc $t$ tests revealed that participants in the $20 \%$ PC condition responded more slowly to incongruent stimuli $(M=442 \mathrm{~ms}, S D=92 \mathrm{~ms})$ than to congruent stimuli $(M=414 \mathrm{~ms}, S D=55 \mathrm{~ms}), t(30)=3.27$, $p=.003, d=0.58$. Also in the $50 \%$-incongruent condition, responses to incongruent stimuli were slower $(M=426 \mathrm{~ms}$, $S D=54 \mathrm{~ms})$ than responses to congruent stimuli $(M=413 \mathrm{~ms}$, $S D=50 \mathrm{~ms}), t(30)=4.21, p<.001, d=0.75$. However, in the $80 \%$-incongruent condition, responses to incongruent stimuli $(M=419 \mathrm{~ms}, S D=36 \mathrm{~ms})$ were not significantly slower than responses to congruent stimuli $(M=423 \mathrm{~ms}, S D=39 \mathrm{~ms})$, $t(31)=1.26, p>.05$ (see Fig. 2, lower panel).

Error rates Error rates mirrored the pattern of the RT analyses. A repeated measures ANOVA with the factors Congruency (congruent, incongruent) and PC (20\% incongruent, $50 \%$ incongruent, $80 \%$ incongruent) yielded a main effect of congruency, $F(1,91)=31.67, p<.001, \eta_{\mathrm{p}}{ }^{2}=.258$. The interaction between congruency and PC was significant, $F(2,91)=22.96, p<.001, \eta_{\mathrm{p}}{ }^{2}=.335$. Participants in the $20 \%$-incongruent condition made more errors in response to incongruent color words $(M=9.7 \%, S D=8.5 \%)$ than to congruent stimuli $(M=3.1 \%, S D=4.9 \%), t(30)=5.74$, $p<.001, d=1.03$. Also in the $50 \%$-incongruent condition, incongruent color words caused more errors $(M=5.4 \%$, $S D=5.6 \%)$ than did responses to congruent stimuli $(M=3.3 \%, S D=5.2 \%), t(30)=6.06, p<.001, d=1.09$. However, the congruency effect was not significantly reversed in the $80 \%$-incongruent condition. Here, errors were less frequent for incongruent color words $(M=3.7 \%, S D=2.6 \%)$ than for congruent color words $(M=4.6 \%, S D=4.3 \%)$, $t(31)=1.38, p>.05$.

\section{Experiment $2 b$}

Reaction times Response anticipations (0.3\%), omissions $(0.5 \%)$, wrong responses $(3.3 \%)$, and RTs that deviated more than three $S D$ s from the corresponding cell mean (1.8\%) were removed from the RT analyses. A repeated measures ANOVA with the factors Congruency (congruent, incongruent) and PC (20\% incongruent, $50 \%$ incongruent, $80 \%$ incongruent) yielded a main effect of congruency, $F(1,64)=16.27$, $p<.001, \eta_{\mathrm{p}}{ }^{2}=.203$. More importantly, the interaction between congruency and PC was significant, $F(2,64)=6.12$, $p=.004, \eta_{\mathrm{p}}{ }^{2}=.161$ (see Fig. 3, lower panel). Post-hoc $t$ tests revealed that participants in the $20 \%$-incongruent condition responded more slowly to incongruent color words $(M=424 \mathrm{~ms}, S D=84 \mathrm{~ms})$ than to congruent color words 

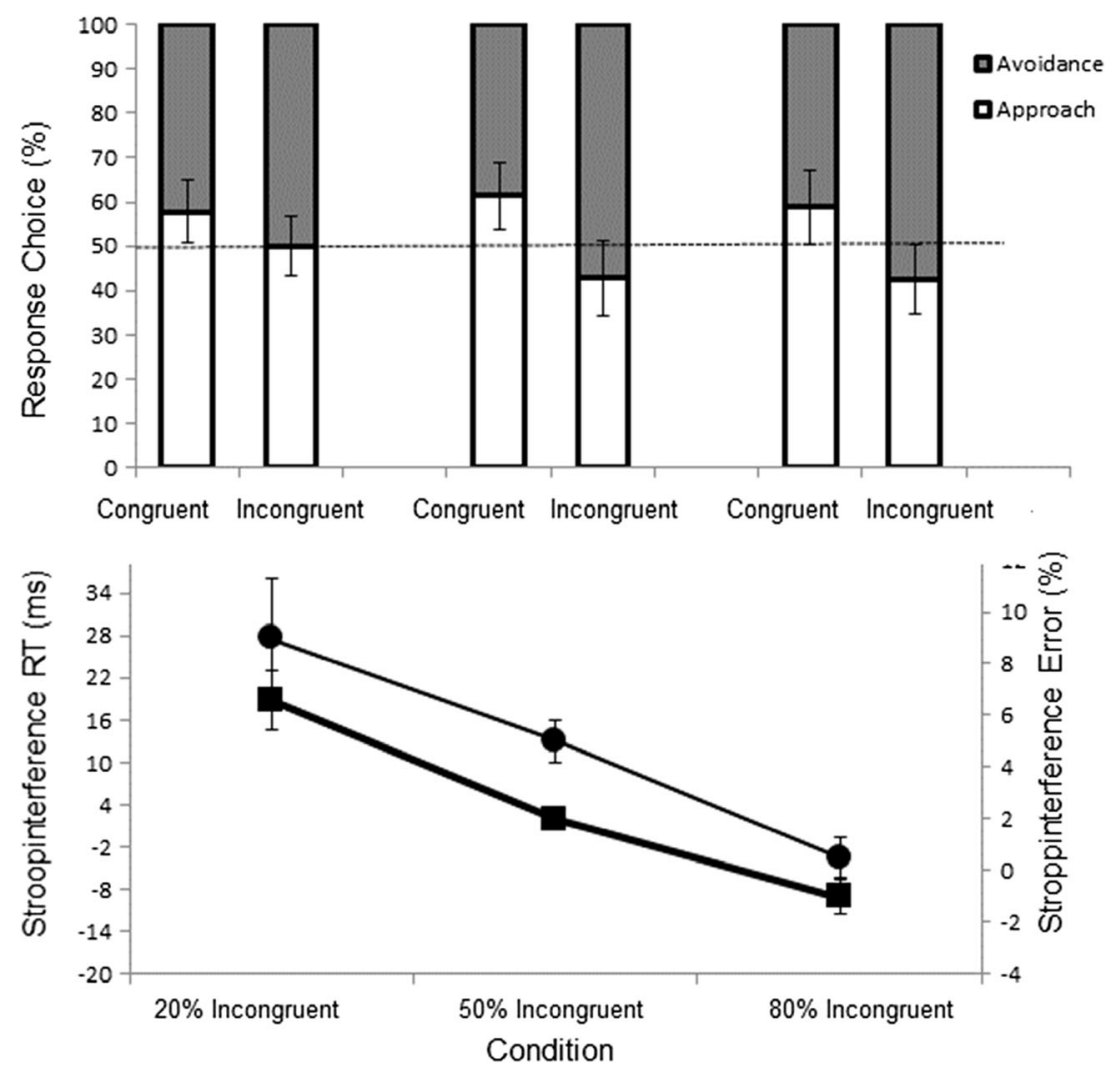

Fig. 2 Experiment 2a results. (Upper panel)Choice of approach- and avoidance-related responses in each proportion congruency condition (20\%, $50 \%$, or $80 \%$ incongruent). (Lower panel)Stroop interference effects for mean RTs (circles) and errors (squares). Error bars show standard errors of the paired differences (Pfister \& Janczyk, 2013)

$S D=3.7 \%$, although the reversal of the congruency effect did not reach the level of significance, $t(20)=1.23, p>.05$.

\section{AAT}

\section{Experiment $2 a$}

Trials with response anticipations $(0.9 \%)$ or response omissions $(2.8 \%)$ and trials with joystick movements to the left or right $(2.4 \%)$ were removed from the analyses. Participants made only a few error responses in no-go trials $(M=2.4 \%$, $S D=3.1 \%$ ).

Response choice Figure 2 (upper panel) depicts the results of the response choices. A repeated measures ANOVA with the factors Congruency (congruent, incongruent) and PC (20\% incongruent, $50 \%$ incongruent, $80 \%$ incongruent) revealed a significant main effect of congruency, $F(1,91)=19.63$, $p<.001, \eta_{\mathrm{p}}{ }^{2}=.177$. Approach responses were favored over avoidance responses for congruent color words $(M=59.7 \%$, $S D=21.6 \%), t(93)=4.36, p<.001, d=0.45$. In contrast, avoidance responses were selected more often in response to incongruent color words $(M=55.3 \%, S D=21.9 \%), t(93)=$ $2.36, p=.02, d=0.24$. The interaction between congruency 


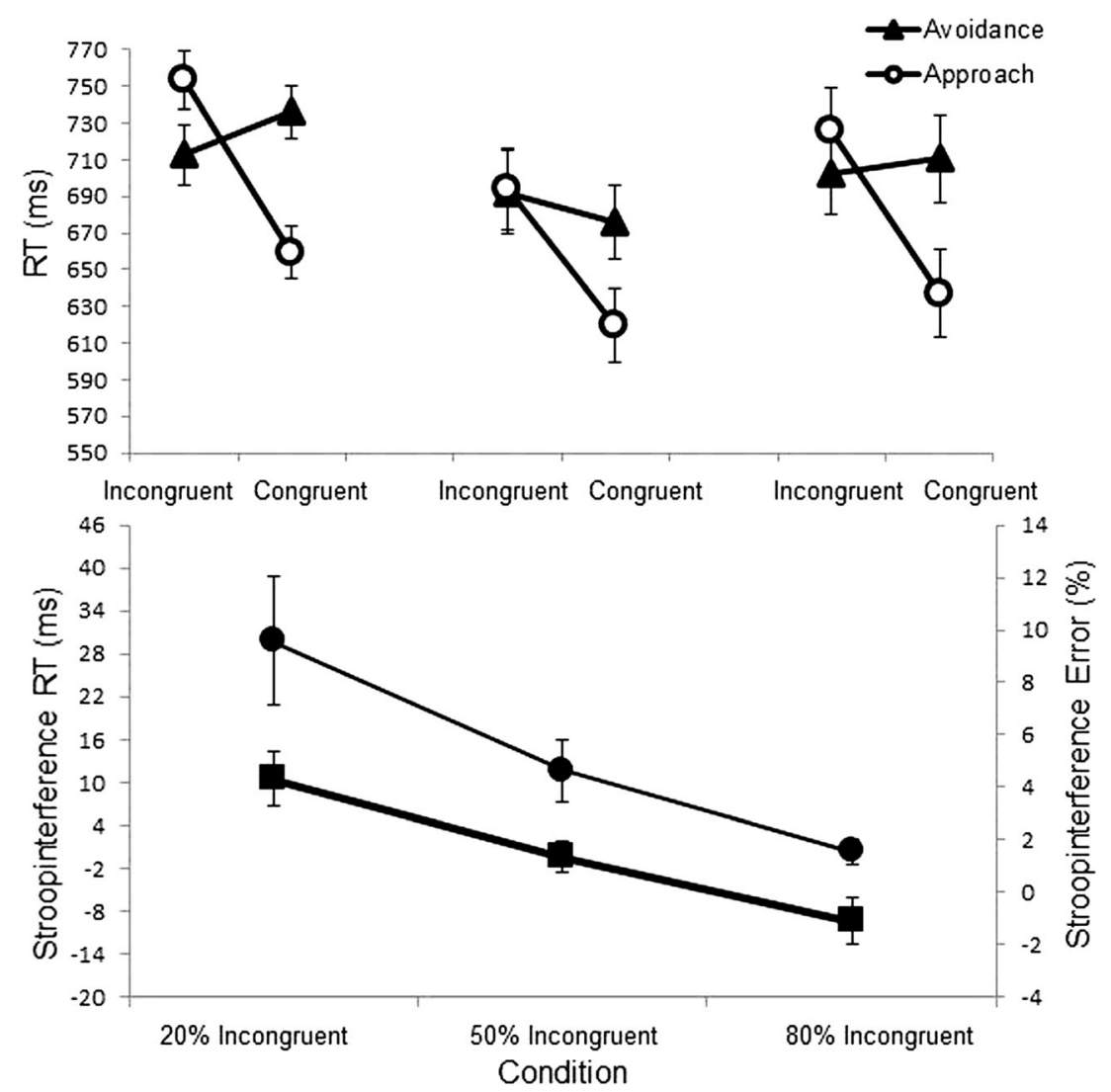

Fig. 3 Experiment $2 b$ results. (Upper panel)Mean RT as a function of stimulus congruency and response type for the forced-choice AAT in each proportion congruency condition $(20 \%, 50 \%$, or $80 \%$ incongruent).
(Lower panel)Stroop interference effects for mean RTs (circles) and errors (squares). Error bars show standard errors of the paired differences (Pfister \& Janczyk, 2013) and PC was not significant, $F(2,91)=1.10, p>.05$, $\eta_{\mathrm{p}}^{2}=.024$.

\section{Experiment $2 b$}

Trials with response anticipations (3.1\%), omissions ( $0.3 \%)$, joystick movements to the left or right (3.5\%), and RTs that deviated more than three $S D$ s from the corresponding cell mean $(1.1 \%)$ were removed from the RT analyses.

A mixed repeated measures ANOVA with the betweensubjects factor PC (20\% incongruent, $50 \%$ incongruent, $80 \%$ incongruent) and the within-subjects factors Congruency (congruent, incongruent), Response Type (approach, avoidance), and Stimulus Type (trained, new) yielded a main effect of congruency, $F(1,64)=139.98, p<.001$, $\eta_{\mathrm{p}}{ }^{2}=.686$, with faster reactions in congruent trials $(M=$ $673 \mathrm{~ms})$ than in incongruent trials $(M=713 \mathrm{~ms})$. The main effect of response type was also significant, $F(1,64)=39.74$, $p<.001, \eta_{\mathrm{p}}{ }^{2}=.383$. Approach responses were generally executed faster than avoidance movements $(M \mathrm{~s}=681 \mathrm{vs} .705 \mathrm{~ms})$. Replicating previous results, the interaction between congruency and response type was significant, $F(1,64)=17.33, p<.001$, $\eta_{\mathrm{p}}{ }^{2}=.213$ (see Fig. 3, upper panel). Participants were faster to approach congruent (one-color) words $(M=638 \mathrm{~ms}$, $S D=104 \mathrm{~ms}$ ) than to approach incongruent (two-color) words ( $M=725 \mathrm{~ms}, S D=124 \mathrm{~ms}), t(66)=7.83, p<.001, d=0.96$. The speeds of avoidance responses did not differ significantly between incongruent (two-color) words $(M=702 \mathrm{~ms}$, $S D=108 \mathrm{~ms})$ and congruent (one-color) words $(M=708 \mathrm{~ms}$, $S D=123 \mathrm{~ms}),|t|<1$. Importantly, neither the three-way interaction between congruency, response type, and PC, nor any interaction with the factor Stimulus Type reached significance (all $p \mathrm{~s}>.11)$.

Error rates An analogous repeated measures ANOVA with the factors PC (20\% incongruent, $50 \%$ incongruent, $80 \%$ incongruent), Congruency (congruent, incongruent), Response Type (approach, avoidance), and Stimulus Type (trained, new) yielded a main effect of congruency, $F(1,64)=15.62, p<.001$, $\eta_{\mathrm{p}}{ }^{2}=.196$, and a main effect of response type, $F(1,64)=4.40, p$ $=.04, \eta_{\mathrm{p}}{ }^{2}=.064$. Participants made fewer errors in congruent trials $(M=7.4 \%)$ than in incongruent trials $(M=9.2 \%)$, and made more errors during avoidance $(M=8.8 \%)$ than during approach $(M=7.7 \%)$ movements. The interaction between congruency and response type was significant, $F(1,64)=$ 21.01, $p<.001, \eta_{\mathrm{p}}{ }^{2}=.247$. Follow-up $t$ tests revealed that 
approach responses to congruent stimuli (one-color words) were less error-prone $(M=6.2 \%, S D=4.8 \%)$ than approach responses to incongruent stimuli (two-color words) $(M=11.3 \%, S D=8.0 \%), t(66)=5.49, p<.001, d=0.67$. In contrast, avoidance responses to incongruent (two-color) words $(M=7.0 \%, S D=6.0 \%)$ were marginally less errorprone than avoidance responses to congruent (one-color) words $(M=8.5 \%, S D=5.7 \%), t(66)=1.97, p=.053, d=0.24$. Corroborating the results of the RT analysis, Stimulus Type and PC did not interact with any other factors (all $p$ s $>$.14).

\section{Discussion}

Experiments $2 \mathrm{a}$ and $2 \mathrm{~b}$ tested whether manipulating the conflict strength during the Stroop task affects the conflictavoidance bias in the AAT. First, we predicted that a high (vs. a low) proportion of incongruent trials should decrease (vs. increase) the Stroop effect. The results were as expected and confirmed that the PC manipulation was successful. Second, according to a conflict-learning account, different levels of conflict - as induced by the PC manipulationshould affect the conflict-avoidance bias in the AAT: a high (vs. low) proportion of incongruent trials should decrease (vs. increase) the avoidance response to incongruent stimuli, relative to a baseline. This prediction was not confirmed. In Experiment 2a (free-choice AAT) and Experiment $2 b$ (forced choice), the conflict-avoidance bias was unaffected by the PC manipulation. Third, the conflict-learning account assumes a transfer from the Stroop task to the AAT. Accordingly, conflict learning predicted a conflict-avoidance bias for trained color words, but not for untrained color words. However, in Experiment $2 \mathrm{~b}$ the conflict-avoidance biases were similar for trained and untrained color words. In sum, these results are incompatible with the conflict-learning account and favor the stimulus-conflict account. Now, Experiment 3 was set up to provide a more conclusive test of the stimulus-conflict account, by manipulating the type of task that preceded the AAT.

\section{Experiment 3}

Groups of participants worked on two different interference tasks before completing a free-choice AAT. One group worked on a standard color Stroop task, and a second group performed a spatial Simon task. In this condition, participants classified the color of a letter " $X$ " that appeared at left and right locations on the screen. We choose a Simon task as a control task because its task procedure resembles that of a Stroop task in many respects, with the crucial difference that no color words are presented in this task. Thus, associations between color words and conflict levels would only be possible for the Stroop task, but not for the Simon task. If learning of stimulus-conflict associations is causal to a conflictavoidance bias in the AAT, as the conflict-learning account suggests, then a conflict-avoidance bias should be observed in the group working on the Stroop task, but not in the group working on the Simon task. The stimulus-conflict account, by contrast, would expect a conflict-avoidance bias in the AAT that was triggered by incongruent stimulus features, irrespective of the interference task.

\section{Method}

\section{Participants}

Sixty-two students (six left-handed; 45 women, 17 men; mean age $=27.0$ years, range: $18-62$ years) were randomly assigned to two conditions. The data of two participants were removed due to unusually high error rates in the AAT $(M \mathrm{~s} \geq 34 \% ;>3$ $S D$ s beyond the group mean of $2.4 \%$ ).

\section{Stimuli and procedure}

The same color words as in the previous experiments were used for the Stroop task and the AAT. One group of participants performed a standard color Stroop task with $50 \%$ congruent and $50 \%$ incongruent trials, following the procedure of Experiment 2a; the other group performed a Simon task in which they had to respond to the color of a white or pink letter "X" presented at a left or a right location on the screen by pressing the same response keys. The participants in both groups performed 192 trials of the respective task. The assignment of colors to the responses was counterbalanced across participants in both tasks. In the subsequent AAT (free-choice procedure, identical to that of Exp. 2a), two congruent and two incongruent color words were presented that were identical to those presented in the Stroop task. The AAT consisted of 96 trials, with presentations of 24 incongruent and 24 congruent color words and 48 no-go trials.

\section{Results}

\section{Stroop task}

Reaction times Trials with anticipations ( $0.3 \%)$, omissions $(0.9 \%)$, wrong responses $(3.8 \%)$, and RTs that deviated more than three $S D$ s from the corresponding cell mean $(1.6 \%)$ were removed from the RT analyses. Responses to incongruent stimuli were slower $(M=417 \mathrm{~ms}, S D=64 \mathrm{~ms})$ than responses to congruent stimuli $(M=402 \mathrm{~ms}, S D=50 \mathrm{~ms}), t(32)=3.67$, $p<.001, d=0.63$ 
Error rates Errors were more frequent in incongruent trials $(M=6.6 \%, S D=13.2 \%)$ than in congruent trials $(M=3.4 \%$, $S D=3.2 \%$ ), although this difference was not significant, $t(32)$ $=1.34, p>.05$.

\section{AAT}

Trials with response anticipations $(<100 \mathrm{~ms} ; 0.1 \%)$ or response omissions $(0.3 \%)$ and trials with joystick movements in the left and right directions $(0.1 \%)$ were removed from the analyses. Participants made only a few error responses in nogo trials $(M=0.9 \%, S D=2.8 \%)$.

Response choice A repeated measures ANOVA with the factors Congruency (congruent, incongruent) and Conflict Task (Stroop vs. Simon) yielded a main effect of congruency, $F(1$, $58)=9.65, p=.003, \eta_{\mathrm{p}}{ }^{2}=.143$. Participants selected approach more often than avoidance in response to congruent color words $(M=56.7 \%, S D=18.6 \%), t(59)=2.80, p=$ $.007, d=0.36$; avoidance was selected more often than approach in response to incongruent color words $(M=52.6 \%$, $S D=19.8 \%$ ), although this effect did not reach significance, $t(59)=1.03, p>.05$. Importantly, the interaction between congruency and conflict task was not significant, $F(1,58)=$ $1.08, p>.05$ (see Fig. 4).

\section{Discussion}

In Experiment 3, we tested a stimulus-conflict account against conflict learning. The conflict-learning account hypothesizes that participants learn in a conflict task to associate incongruent items with conflict, and that these memories trigger avoidance of these items in the AAT. Thus, a conflict-avoidance

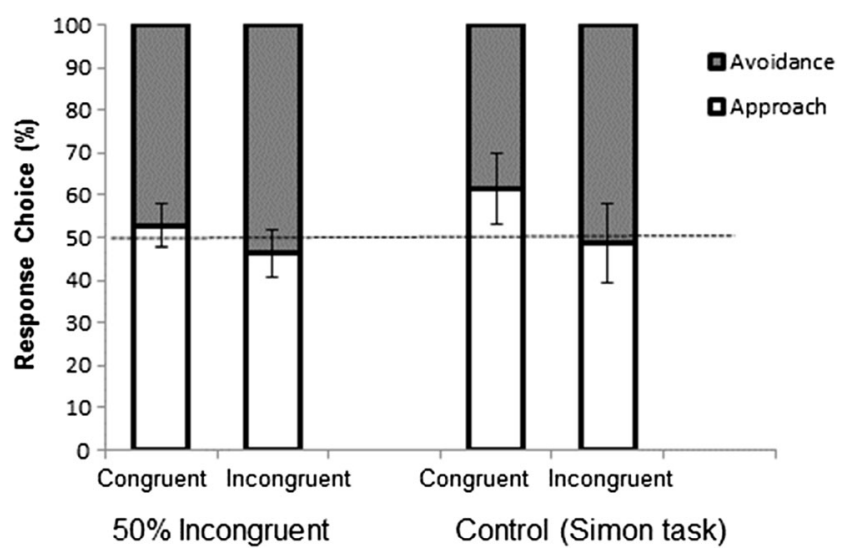

Fig. 4 Mean response choices for congruent and incongruent stimuli in Experiment 3, in a free-choice AAT that was preceded by a Stroop task (left bars) and in a control condition in which the free-choice AAT was preceded by a Simon task (right panel). Error bars show standard errors of the paired differences (Pfister \& Janczyk, 2013) bias results from learning processes during the Stroop task. The stimulus-conflict account, in contrast, assumes that a conflict-avoidance bias is induced by conflicting stimulus information (here: incongruent color words) without prior learning. The results clearly supported the stimulus-conflict account and not the conflict-learning account, because a conflict bias was observed in both conditions, irrespective of the type of conflict task that preceded the AAT. Thus, stimulus conflict is sufficient to induce an avoidance tendency.

\section{General discussion}

In this research, we examined the motivational consequences of conflict processing. As a probe for motivational action tendencies, an approach-avoidance task was used in which we measured the choice and speed of approach- and avoidancerelated lever movements in response to conflicting (incongruent) and nonconflicting (congruent) color words. In four experiments, we observed a bias to select approach over avoidance movements in response to nonconflict stimuli, and to select avoidance over approach movements in response to conflict stimuli. This conflict-avoidance bias effect was not modulated by manipulations of response conflict in a preceding Stroop task (Exps. 2a and 2b). Furthermore, incongruent Stroop items triggered an avoidance tendency even without a corresponding conflict experience in a foregoing conflict task, suggesting that memories of conflict are not causal for the motivational bias. In combination, these results demonstrate that the processing of conflicting stimulus features is sufficient to trigger an avoidance tendency.

\section{The relationship between conflict and avoidance}

Several studies have provided evidence for a negative evaluation of conflict (Dreisbach \& Fischer, 2012; see also Fritz \& Dreisbach, 2013, 2015; Schouppe et al., 2015, Exp. 1) and for avoidance of conflict (Schouppe et al., 2012). However, the interpretation of previous studies that have reported evidence for an affective or motivational quality of conflict has been ambiguous, because nonconflict stimuli were presented more frequently than conflict stimuli at the item level. Thus, it could not be ruled out that the affective evaluation of the stimuli was confounded with mere-exposure effects that have been known to exert an influence on affective judgments. By controlling for stimulus frequency, the present study has confirmed the conclusions of previous research and provided unequivocal evidence for the motivational consequences of conflict. Furthermore, the present results are in line with previous work on a reverse influence of avoidance motivation on cognitive control processes. For instance, several studies have obtained evidence that the activation of an avoidance state (by extending the arm or making a backward step) promotes cognitive 
control (as indexed by a reduced interference effect in a Stroop task; Koch, Holland, Hengstler, \& van Knippenberg, 2009; Koch, Holland, \& van Knippenberg, 2008; see also Hengstler, Holland, van Steenbergen, \& van Knippenberg, 2014). Given that the primary concern of avoidance motivation is coping with threats and challenges (Eder, Elliot, \& Harmon-Jones, 2013), a bidirectional connection between cognitive control processes and avoidance motivation is plausible. Research has also suggested that the detection and resolution of conflict elicit distinct affective responses that change dynamically during the pursuit of a task. In line with this suggestion, studies have shown that the resolution of cognitive conflict is positive (Schouppe et al., 2015) and that the resolution of a strong conflict is even more rewarding (Satterthwaite et al., 2012; Schouppe, Demanet, Boehler, Ridderinkhof, \& Notebaert, 2014). Thus, several research lines converge on the conclusion that cognitive and affective control processes are closely intertwined and subject to mutual influence.

\section{Avoidance of conflicting stimuli or responses (or both)?}

The conflict-monitoring theory of Botvinick and colleagues (2001) quantified conflict in terms of crosstalk at the output (response) level. Consequently, conflicting responses - and not conflicting stimulus features - should produce an aversive signal, according to this theory. The present results, however, point out that incongruent stimulus features without response conflict are sufficient to induce an avoidance bias. Thus, crosstalk at the input level seems to be sufficient to trigger motivational responses. This is line with studies on the affective evaluation of stimulus conflict (Fritz \& Dreisbach, 2013). Interestingly, stimulus conflict and response conflict have been shown to activate different regions of the ACC. In a study by van Veen and Carter (2005), (Stroop) stimulus conflict was associated with stronger activation in a caudal part of the dorsal ACC (BA 32/6), whereas response conflict was associated with stronger activation in the more rostral dorsal ACC (BA 32/24; for related findings, see Z. Chen, Lei, Ding, Li, \& Chen, 2013; Kim, Kroger, \& Kim, 2011). This functional dissociation is in line with accounts that have proposed a modular architecture of cognitive control, with separate modules for the resolution of stimulus and response conflicts (Egner,
2008; Egner, Delano, \& Hirsch, 2007). Although it has been suggested that only the more rostral part of the ACC is specialized for affective processes (Bush, Luu, \& Posner, 2000), recent meta-analyses have favored an integrative view of both ACC regions as being a general hub for pain, negative affect, and conflict (Etkin, Egner, \& Kalisch, 2011; Shackman et al., 2011). Thus, it remains an open question whether separate conflict modules harness negative affect as a common currency for control adjustments, or whether negative affect is a specific signal related only to stimulus conflict.

\section{Interindividual differences in conflict processing}

The correlations observed in Experiments 1a and $1 \mathrm{~b}$ suggest that the magnitude of conflict in a preceding Stroop task is related to the avoidance tendency exhibited in the motivational test (AAT). However, our experimental variations of conflict strength in Experiments $2 \mathrm{a}$ and $2 \mathrm{~b}$ failed to confirm this relationship. What accounts, then, for the observed correlations? One plausible explanation is that participants differed in their sensitivities to conflicting stimulus features during the processing of incongruent color words in both tasks, which explains a correlation between the Stroop interference effect and the size of conflict avoidance. To further examine this possibility, we combined the data from all experiments and correlated the Stroop interference effects (RTs, errors) with the conflictavoidance biases observed in both variants of the AAT. The results revealed significant positive correlations for both AAT versions. As is shown in Table 1, participants who displayed stronger Stroop interference also exhibited an enhanced avoidance tendency in the AAT. Dispositional variables such as trait anxiety (Fowles, 1980) or activity of the behavioral inhibition/ behavioral activation system (BIS/BAS; Gray \& McNaughton, 2000) can account for this relationship. For instance, it has been shown that individuals with high trait anxiety/high trait BIS show a particularly strong reaction to conflict (Amodio, Master, Yee, \& Taylor, 2008; Leue, Lange, \& Beauducel, 2012), and that individuals who express high levels of negative affect or report more anxiety have a stronger physiological response to errors (Hajcak \& Foti, 2008; Hajcak, McDonald, \& Simons, 2003). Amodio et al. suggested that conflict monitoring interacts with BIS via noradrenergic input from the locus

Table 1 Correlations between Stroop performance and the conflict-avoidance biases (see Exp. 1 for a description how the index was calculated) for Experiments 1-3, shown separately for forced-choice and free-choice AATs

\begin{tabular}{llll}
\hline & \multicolumn{2}{l}{ Forced-Choice AAT $(N=109)$} & Free-Choice AAT $(N=177)$ \\
\cline { 2 - 4 } Correlated Variable & RT $(\mathrm{ms})$ & Error Rate $(\%)$ & Response Choice $(\%)$ E \\
\hline Stroop interference RT $(\mathrm{ms})$ & $.166^{*}$ & .083 & -.002 \\
Stroop interference error $(\%)$ & $.209^{*}$ & $.377^{* * *}$ & $.143^{* 1}$ \\
\hline
\end{tabular}

\footnotetext{
${ }^{1}$ Note that this correlation was not significant $(r=-.043, p=.578$, one-sided) following correction for outlier values (i.e., the Stroop interference effects or AAT scores of six participants who deviated more than three $S D$ s from the respective mean). ${ }^{*} p<.05,{ }^{* * *} p<.001$ (one-sided)
} 
coeruleus-norepinephrine system. Phasic release of norepinephrine from the locus coeruleus is considered to be responsible for the maintenance of stable task performance by projecting to the ACC (Aston-Jones \& Cohen, 2005), and this has been the focus of a model of cognitive control (Verguts \& Notebaert, 2009). Clearly, further research is needed that can go beyond correlational evidence to clarify the relationship between dispositional variables and cognitive control.

To summarize, the present study has provided a more conclusive test of the relationship between experiences of conflict in Stroop tasks and avoidance motivation, by ruling out mere exposure as an alternative explanation (Exps. 1a and 1b). Furthermore, Experiments 2 and 3 extended previous research on the affective evaluation of conflict to motivational action tendencies by demonstrating that the processing of conflicting stimulus features is sufficient to trigger an avoidance tendency.

\section{References}

Abrahamse, E. L., Duthoo, W., Notebaert, W., \& Risko, E. F. (2013). Attention modulation by proportion congruency: The asymmetrical list shifting effect. Journal of Experimental Psychology: Learning, Memory, and Cognition, 39, 1552-1562.

Amodio, D. M., Master, S. L., Yee, C. M., \& Taylor, S. E. (2008). Neurocognitive components of the behavioral inhibition and activation systems: Implications for theories of self-regulation. Psychophysiology, 45, 11-19.

Aston-Jones, G., \& Cohen, J. D. (2005). An integrative theory of locus coeruleus-norepinephrine function: Adaptive gain and optimal performance. Annual Review of Neuroscience, 28, 403-450. doi:10. 1146/annurev.neuro.28.061604.135709

Berkowitz, L., \& Harmon-Jones, E. (2004). Toward an understanding of the determinants of anger. Emotion, 4, 107-130.

Berridge, K. C., Robinson, T. E., \& Aldridge, J. W. (2009). Dissecting components of reward: "Liking", "wanting", and learning. Current Opinion in Pharmacology, 9, 65-73.

Bornstein, R. F. (1989). Exposure and affect: Overview and meta-analysis of research, 1968-1987. Psychological Bulletin, 106, 265-289.

Botvinick, M. M. (2007). Conflict monitoring and decision making: Reconciling two perspectives on anterior cingulate function. Cognitive, Affective, \& Behavioral Neuroscience, 7, 356-366. doi: 10.3758/CABN.7.4.356

Botvinick, M. M., Braver, T. S., Barch, D. M., Carter, C. S., \& Cohen, J. D. (2001). Conflict monitoring and cognitive control. Psychological Review, 108, 624-652. doi:10.1037/0033-295X.108.3.624

Botvinick, M. M., Cohen, J. D., \& Carter, C. S. (2004). Conflict monitoring and anterior cingulate cortex: An update. Trends in Cognitive Sciences, 8, 539-546. doi:10.1016/j.tics.2004.10.003

Botvinick, M., Nystrom, L. E., Fissell, K., Carter, C. S., \& Cohen, J. D. (1999). Conflict monitoring versus selection-for-action in anterior cingulate cortex. Nature, 402, 179-181. doi:10.1038/46035

Bush, G., Luu, P., \& Posner, M. I. (2000). Cognitive and emotional influences in anterior cingulate cortex. Trends in Cognitive Sciences, 4, 215-222.
Carter, C. S., Botvinick, M. M., \& Cohen, J. D. (1999). The contribution of the anterior cingulate cortex to executive processes in cognition. Reviews in the Neurosciences, 10, 49-58.

Carter, C. S., Braver, T. S., Barch, D. M., Botvinick, M. M., Noll, D., \& Cohen, J. D. (1998). Anterior cingulate cortex, error detection, and the online monitoring of performance. Science, 280, 747-749. doi: $10.1126 /$ science. 280.5364 .747

Carver, C. S. (2004). Negative affects deriving from the behavioral approach system. Emotion, 4, 3-22.

Carver, C. S., \& Harmon-Jones, E. (2009). Anger is an approach-related affect: Evidence and implications. Psychological Bulletin, 135, 183-204. doi:10.1037/a0013965

Chen, M., \& Bargh, J. A. (1997). Nonconscious behavioral confirmation processes: The self-fulfilling consequences of automatic stereotype activation. Journal of Experimental Social Psychology, 33, 541-560.

Chen, Z., Lei, X., Ding, C., Li, H., \& Chen, A. (2013). The neural mechanisms of semantic and response conflicts: An fMRI study of practicerelated effects in the Stroop task. NeuroImage, 66, 577-584.

Cohen, J. D., Dunbar, K., \& McClelland, J. L. (1990). On the control of automatic processes: A parallel distributed processing account of the Stroop effect. Psychological Review, 97, 332-361. doi:10.1037/ 0033-295X.97.3.332

Dreisbach, G., \& Fischer, R. (2012). Conflicts as aversive signals. Brain and Cognition, 78, 94-98. doi:10.1016/j.bandc.2011.12.003

Eder, A. B., Elliot, A. J., \& Harmon-Jones, E. (2013). Approach and avoidance motivation: Issues and advances. Emotion Review, 5, 227-229.

Eder, A. B., \& Rothermund, K. (2008). When do motor behaviors (mis)match affective stimuli? An evaluative coding view of approach and avoidance reactions. Journal of Experimental Psychology: General, 137, 262-281. doi:10.1037/0096-3445.137.2.262

Egner, T. (2008). Multiple conflict-driven control mechanisms in the human brain. Trends in Cognitive Sciences, 12, 374-380. doi:10. 1016/j.tics.2008.07.001

Egner, T., Delano, M., \& Hirsch, J. (2007). Separate conflict-specific cognitive control mechanisms in the human brain. NeuroImage, 35, 940-948. doi:10.1016/j.neuroimage.2006.11.061

Egner, T., \& Hirsch, J. (2005). Cognitive control mechanisms resolve conflict through cortical amplification of task-relevant information. Nature Neuroscience, 8, 1784-1790. doi:10.1038/nn1594

Eisenberger, N. I., Lieberman, M. D., \& Williams, K. D. (2003). Does rejection hurt? An fMRI study of social exclusion. Science, 302, 290-292. doi:10.1126/science.1089134

Elliot, A. J., \& Maier, M. A. (2007). Color and psychological functioning. Current Directions in Psychological Science, 16, 250-254.

Elsner, B., \& Hommel, B. (2001). Effect anticipation and action control. Journal of Experimental Psychology: Human Perception and Performance, 27, 229-240. doi:10.1037/0096-1523.27.1.229

Eriksen, B. A., \& Eriksen, C. W. (1974). Effects of noise letters upon the identification of a target letter in a nonsearch task. Perception \& Psychophysics, 16, 143-149. doi:10.3758/BF03203267

Etkin, A., Egner, T., \& Kalisch, R. (2011). Emotional processing in anterior cingulate and medial prefrontal cortex. Trends in Cognitive Sciences, 15, 85-93.

Fazio, R. H., Sanbonmatsu, D. M., Powell, M. C., \& Kardes, F. R. (1986). On the automatic activation of attitudes. Journal of Personality and Social Psychology, 50, 229-238. doi:10.1037/0022-3514.50.2.229

Fowles, D. C. (1980). The three arousal model: Implications of Gray's two-factor learning theory for heart rate, electrodermal activity, and psychopathy. Psychophysiology, 17, 87-104.

Fritz, J., \& Dreisbach, G. (2013). Conflicts as aversive signals: Conflict priming increases negative judgments for neutral stimuli. Cognitive, Affective, \& Behavioral Neuroscience, 13, 311-317. doi:10.3758/ s13415-012-0147-1 
Fritz, J., \& Dreisbach, G. (2015). The time course of the aversive conflict signal. Experimental Psychology, 62, 30-39. doi:10.1027/16183169/a000271

Gray, J. A., \& McNaughton, N. (2000). The neuropsychology of anxiety. Oxford: Oxford University Press.

Hajcak, G., \& Foti, D. (2008). Errors are aversive defensive motivation and the error-related negativity. Psychological Science, 19, 103 108. doi:10.1111/j.1467-9280.2008.02053.x

Hajcak, G., McDonald, N., \& Simons, R. F. (2003). To err is autonomic: Error-related brain potentials, ANS activity, and post-error compensatory behavior. Psychophysiology, 40, 895-903. doi:10.1111/14698986.00107

Harmon-Jones, E., Harmon-Jones, C., \& Price, T. F. (2013). What is approach motivation? Emotion Review, 5, 291-295.

Hengstler, M., Holland, R. W., van Steenbergen, H., \& van Knippenberg, A. (2014). The influence of approach-avoidance motivational orientation on conflict adaptation. Cognitive, Affective, \& Behavioral Neuroscience, 14, 548-560. doi:10. 3758/s13415-014-0295-6

Holroyd, C. B., \& Coles, M. G. H. (2002). The neural basis of human error processing: Reinforcement learning, dopamine, and the errorrelated negativity. Psychological Review, 109, 679-709. doi:10. 1037/0033-295X.109.4.679

Holroyd, C. B., \& Yeung, N. (2012). Motivation of extended behaviors by anterior cingulate cortex. Trends in Cognitive Sciences, 16, 122 128. doi:10.1016/j.tics.2011.12.008

Kim, C., Kroger, J. K., \& Kim, J. (2011). A functional dissociation of conflict processing within anterior cingulate cortex. Human Brain Mapping, 32, 304-312.

Koch, S., Holland, R. W., Hengstler, M., \& van Knippenberg, A. (2009). Body locomotion as regulatory process: Stepping backward enhances cognitive control. Psychological Science, 20, 549-550. doi: 10.1111/j.1467-9280.2009.02342.x

Koch, S., Holland, R. W., \& van Knippenberg, A. (2008). Regulating cognitive control through approach-avoidance motor actions. Cognition, 109, 133-142.

Kornblum, S., Hasbroucq, T., \& Osman, A. (1990). Dimensional overlap: Cognitive basis for stimulus-response compatibility - A model and taxonomy. Psychological Review, 97, 253-270. doi:10.1037/0033295X.97.2.253

Leue, A., Lange, S., \& Beauducel, A. (2012). Modulation of the conflict monitoring intensity: The role of aversive reinforcement, cognitive demand, and trait-BIS. Cognitive, Affective, \& Behavioral Neuroscience, 12, 287-307.

Lindsay, D. S., \& Jacoby, L. L. (1994). Stroop process dissociations: The relationship between facilitation and interference. Journal of Experimental Psychology: Human Perception and Performance, 20, 219-234. doi:10.1037/0096-1523.20.2.219

Logan, G. D., \& Zbrodoff, N. J. (1979). When it helps to be misled: Facilitative effects of increasing the frequency of conflicting stimuli in a Stroop-like task. Memory \& Cognition, 7, 166-174. doi:10. 3758/BF03197535

MacLeod, C. M. (1991). Half a century of research on the Stroop effect: An integrative review. Psychological Bulletin, 109, 163-203. doi: 10.1037/0033-2909.109.2.163

Németh, G., Hegedüs, K., \& Molnâr, L. (1988). Akinetic mutism associated with bicingular lesions: Clinicopathological and functional anatomical correlates. European Archives of Psychiatry and Neurological Sciences, 237, 218-222.

Ochsner, K. N., \& Gross, J. J. (2008). Cognitive emotion regulation: Insights from social cognitive and affective neuroscience. Current Directions in Psychological Science, 17, 153-158. doi:10.1111/j. 1467-8721.2008.00566.x

Pfister, R., \& Janczyk, M. (2013). Confidence intervals for two sample means: Calculation, interpretation, and a few simple rules. Advances in Cognitive Psychology, 9, 74-80.
Rainville, P. (2002). Brain mechanisms of pain affect and pain modulation. Current Opinion in Neurobiology, 12, 195-204.

Rinck, M., \& Becker, E. S. (2007). Approach and avoidance in fear of spiders. Journal of Behavior Therapy and Experimental Psychiatry, $38,105-120$

Satterthwaite, T. D., Wolf, D. H., Loughead, J., Ruparel, K., Elliott, M. A., Hakonarson, H., . . . Gur, R. E. (2012). Impact of in-scanner head motion on multiple measures of functional connectivity: Relevance for studies of neurodevelopment in youth. NeuroImage, 60, 623632. doi:10.1016/j.neuroimage.2011.12.063

Scholer, A. A., \& Higgins, E. T. (2008). People as resources: Exploring the functionality of warm and cold. European Journal of Social Psychology, 38, 1111-1120.

Schouppe, N., Braem, S., De Houwer, J., Silvetti, M., Verguts, T., Ridderinkhof, K. R., \& Notebaert, W. (2015). No pain, no gain: The affective valence of congruency conditions changes following a successful response. Cognitive, Affective, \& Behavioral Neuroscience, 15, 251-261. doi:10.3758/s13415-014-0318-3

Schouppe, N., De Houwer, J., Ridderinkhof, K. R., \& Notebaert, W. (2012). Conflict: Run! Reduced Stroop interference with avoidance responses. Quarterly Journal of Experimental Psychology, 65, 1052-1058. doi:10.1080/17470218.2012.685080

Schouppe, N., Demanet, J., Boehler, C. N., Ridderinkhof, K. R., \& Notebaert, W. (2014). The role of the striatum in effort-based decision-making in the absence of reward. Journal of Neuroscience, 34, 2148-2154. doi:10.1523/JNEUROSCI. 1214-13.2014

Shackman, A. J., Salomons, T. V., Slagter, H. A., Fox, A. S., Winter, J. J., \& Davidson, R. J. (2011). The integration of negative affect, pain and cognitive control in the cingulate cortex. Nature Reviews Neuroscience, 12, 154-167.

Shenhav, A., Botvinick, M. M., \& Cohen, J. D. (2013). The expected value of control: An integrative theory of anterior cingulate cortex function. Neuron, 79, 217-240. doi:10.1016/ j.neuron.2013.07.007

Simon, J. R. (1969). Reactions toward the source of stimulation. Journal of Experimental Psychology, 81, 174-176. doi:10.1037/h0027448

Singer, T., Seymour, B., O’Doherty, J., Kaube, H., Dolan, R. J., \& Frith, C. D. (2004). Empathy for pain involves the affective but not sensory components of pain. Science, 303, 1157-1162. doi:10.1126/ science. 1093535

Stroop, J. R. (1935). Studies of interference in serial verbal reactions. Journal of Experimental Psychology, 18, 643-662. doi:10.1037/ 0096-3445.121.1.15

Stürmer, B., Leuthold, H., Soetens, E., Schröter, H., \& Sommer, W. (2002). Control over location-based response activation in the Simon task: Behavioral and electrophysiological evidence. Journal of Experimental Psychology: Human Perception and Performance, 28, 1345-1363. doi:10.1037/0096-1523.28.6.1345

Torres-Quesada, M., Funes, M. J., \& Lupiáñez, J. (2013). Dissociating proportion congruent and conflict adaptation effects in a Simon-Stroop procedure. Acta Psychologica, 142, 203-210.

Torres-Quesada, M., Lupiáñez, J., Milliken, B., \& Funes, M. J. (2014). Gradual proportion congruent effects in the absence of sequential congruent effects. Acta Psychologica, 149, 78-86.

Tzelgov, J., Henik, A., \& Berger, J. (1992). Controlling Stroop effects by manipulating expectations for color words. Memory \& Cognition, 20, 727-735. doi:10.3758/BF03202722

van Veen, V., \& Carter, C. S. (2005). Separating semantic conflict and response conflict in the Stroop task: A functional MRI study. NeuroImage, 27, 497-504. doi:10.1016/j.neuroimage.2005.04.042

Verguts, T., \& Notebaert, W. (2009). Adaptation by binding: A learning account of cognitive control. Trends in Cognitive Sciences, 13, 252257. doi:10.1016/j.tics.2009.02.007 